\title{
Gram stain and addition of amphotericin B to improve the microbial safety of human donor corneas
}

\author{
Davide Camposampiero - Adriano Fasolo - Giuseppe Saccon • Pietro M. Donisi • \\ Elisa Zanetti · Diego Ponzin
}

Received: 29 June 2021 / Accepted: 7 November 2021/Published online: 17 November 2021

(C) The Author(s) 2021

\begin{abstract}
To determine the effectiveness of two methods to improve the microbial safety of human corneas preserved in organ culture. We compared the number of positive preservation solutions of corneas in organ culture in which the initial short-term hypothermic corneal maintenance solution was supplemented with amphotericin B $2.5 \mu \mathrm{g} / \mathrm{mL}$ and the historical data of microbial test results (2015-2019). In addition, we appraised the efficacy of Gram stain to detect bacterial or fungal contamination in the organ culture solutions of corneas from at-risk donors compared to the culture tests of corneas from not-at-risk donors. Statistical analysis was performed using STATA and statistical
\end{abstract}

D. Camposampiero - A. Fasolo · G. Saccon ·

E. Zanetti $(\bowtie) \cdot$ D. Ponzin

The Veneto Eye Bank Foundation, Padiglione. G. Rama,

Via Paccagnella 11, Zelarino, 30174 Venice, Italy

e-mail: elisa.zanetti@fbov.it

D. Camposampiero

e-mail: davide.camposampiero@fbov.it

A. Fasolo

e-mail: adriano.fasolo@fbov.it

G. Saccon

e-mail: giuseppe.saccon@fbov.it

D. Ponzin

e-mail: diego.ponzin@fbov.it

P. M. Donisi

Pathological Anatomy Unit, SS. Giovanni e Paolo

Hospital, Aulss3 Serenissima, Venice, Italy

e-mail: pietromaria.donisi@aulss3.veneto.it significance set at $p<0.05$. The number of positive culture tests after preservation was $15(0.5 \%)$ in 2020 compared to a mean of $37(1.2 \%)$ in the period 2015-2019 ( $p<0.01)$, with $10(1.0 \%)$ positive samples in the cohort of 998 corneas from at-risk donors and $5(0.2 \%)$ in the 2046 corneas from not-at-risk donors $(p<0.01)$. All corneas from at-risk donors tested positive at Gram stain and the results were available 1-3 days before those of the conventional culture tests. Amphotericin B supplementation in the short-term maintenance solution markedly reduced the number of positive microbial tests after organ culture and the early detection of contaminants, including slow-growing microorganisms, by Gram stain before the standard culture results. This meant fewer corneas being discarded and a greater likelihood of preventing post-graft infections.

Keywords Amphotericin B - Donor cornea - Eye banking $\cdot$ Gram stain $\cdot$ Organ culture $\cdot$ Sterility test

\section{Introduction}

Bacterial and fungal contamination of human donor corneas and the risk of post-keratoplasty infections that merit investigation (Kitazawa et al. 2017; Thareja et al. 2020; Thomas 2003). A study comprising 4410 organ-cultured corneas $\left(31{ }^{\circ} \mathrm{C}\right)$ reported an overall microbial contamination rate of $2.5 \%$, with Candida 
spp. accounting for most contaminations (Ling et al. 2019). According to systematic reporting by the Eye Bank Association of America, the yearly incidence of fungal infection after transplantation of hypothermic preserved corneas rose from $0.009 \%$ between 2005 and 2007 to $0.016 \%$ between 2008 and 2010 (Aldave et al. 2013). Between 2007 and 2014, adverse reactions after corneal transplantation due to fungal infection occurred in half of cases of endophthalmitisand keratitis-associated pathogens, with no statistical difference between endothelial and penetrating keratoplasty (Edelstein et al. 2016).

Microbial testing of organ-culture preservation solutions is key to detecting and discarding contaminated corneas prior to distribution for transplant, whereas postoperative rim culturing is recommended to warn of the potential risk of infection (Camposampiero et al. 2015; EEBA 2020; Zanetti et al. 2005). Although storage solutions contain empiric broad-spectrum antibiotics, organ culture is still subject to microbial contamination due to media composition and conditions conducive to growth: temperature between 30 and $37{ }^{\circ} \mathrm{C}$ and length of preservation time (Thareja et al. 2020). The addition of antibiotics to storage medium is an unreliable remedy due to the increasing antibiotic resistance of contaminating microbes ( $\mathrm{Li}$ et al. 2019a, b).

Moreover, the cause of donor death (e.g., infection or sepsis, respiratory disease, multi-organ failure, cancer) can increase the risk of bacterial and fungal contamination (Armitage et al. 2014; Kramp et al. 2020; Röck et al. 2016), with contamination rates ranging from 2.5 to $6.4 \%$ during organ culture (Fontana et al. 2007; Ling et al. 2019). Nonetheless, the risk of keratitis or endophthalmitis developing in patients transplanted with a contaminated donor cornea is low (1.3\%) (Kiatos et al. 2017).

During organ culture storage of up to 4 weeks, routine microbiological screening is performed by standard culture tests on media or via automatic systems that alert to the detection of microbial growth. We currently sample the preservation medium (Storage) after 6 days of organ culture and then again, following evaluation of suitability for transplantation, at 1 day after the transfer of the cornea into the transport solution (Deswelling-Transport) prior to delivery. The Deswelling-Transport solution is tested once more after processing of the cornea for endothelial or anterior lamellar keratoplasty. For example, between 2015 and 2017 we found Candida spp. (75\%), Gram-positive and Gram-negative bacteria (20\%), and unspecified yeasts and moulds (5\%) in 65 isolates from positive Storage solutions at the end of organ culture. If the Storage solution results positive for microbial contamination at the first sampling period after 6 days, the cornea is discarded. Subsequent tests are performed more or less concomitantly but results may not be ready when the corneal tissue has to be sent to the surgical centre. The time window between full test result availability and delivery of tissue for transplantation is critical, with the risk of distributing unsafe corneas.

Gram stain is a simple, rapid, and low-cost method to detect bacteria, yeasts (Candida and Cryptococcus species), and moulds (Aspergillus species) in biological samples; it is employed to reveal slow-growing microbes or those difficult to culture and to differentiate these species from eukaryotic cells of human origin (Popescu and Doyle 1996). The Gram stain does not depend on the chemical properties of the cell wall but rather on its thickness, which explains why the thicker cells of fungi show crystal violet positive staining despite the chemical composition being different from the cell wall of Gram-positive bacteria (Murray et al. 2012).

The aim of the present study was twofold: to determine the occurrence of contaminated preservation solutions after organ culture in which amphotericin B was added to the solution (Cold) for hypothermic maintenance of corneas (from the retrieval site to the eye bank) before starting organ culture, and to determine the feasibility of Gram stain to detect residual microorganisms in the Storage solution at the end of organ culture.

\section{Methods}

Preservation and processing of donor corneas

Figure 1 illustrates the process for organ culture of donor corneas at our institution. Cold, Storage, and Deswelling-Transport solutions contain MEM-Earle with HEPES $25 \mathrm{mM}$, sodium bicarbonate $26 \mathrm{mM}$, pyruvate $1 \mathrm{mM}$, glutamine $2 \mathrm{mM}$, newborn calf serum $2 \% \mathrm{v} / \mathrm{v}$, penicillin $\mathrm{G} 60 \mu \mathrm{g} / \mathrm{mL}$, and streptomycin $100 \mu \mathrm{g} / \mathrm{mL}$. Amphotericin B $0.25 \mu \mathrm{g} / \mathrm{mL}$ is currently added to the Storage and the Deswelling-Transport 


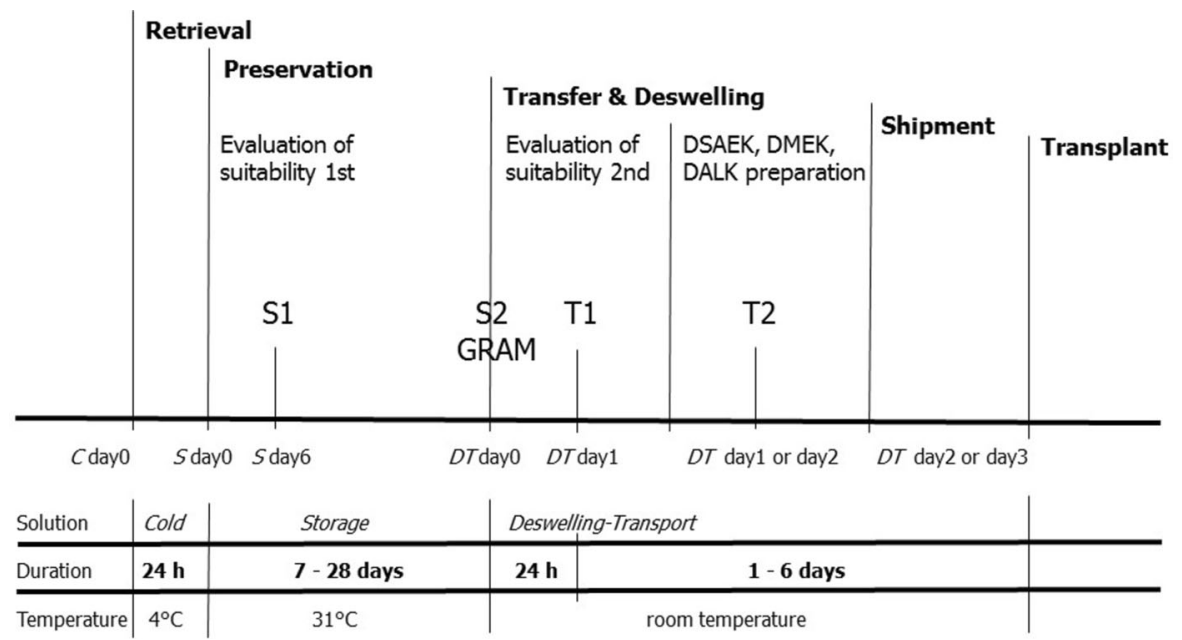

Fig. 1 Phases of the eye bank activities and sterility testing. C denotes Cold; DT, Deswelling-Transport; GRAM, staining with Gram's Method; S, Storage; S1, first sample during preservation in Storage; S2, second samples at the end of preservation and

solution. It has proven efficacy against $C$. albicans in hypothermic conditions at $2-8{ }^{\circ} \mathrm{C}$ (Tran et al. 2020). Beginning in February 2020, we supplemented amphotericin B $2.5 \mu \mathrm{g} / \mathrm{mL}$ to the Cold solution for the short-term hypothermic maintenance of donor corneas before starting preservation in organ culture. Deswelling-Transport contains dextran-T500 6\% w/v and the cornea is maintained for at least $24 \mathrm{~h}$ in this solution to recover transparency and thickness before processing or grafting.

For planned surgeries, we remove corneas from Storage between day 14 and 35 of culture, perform light microscopy and endothelial staining, and transfer those corneas suitable for transplantation into Deswelling-Transport. Corneas for anterior lamellar keratoplasty (ALK) and endothelial keratoplasty (EK) are pre-cut by microkeratome, with the anterior and the posterior portion realigned in their original position for distribution, or Descemet's membrane is manually stripped to separate the ultrathin cornea portion comprising the endothelium for Descemet membrane endothelial keratoplasty (DMEK) and then repositioned on the corneal stroma.

The corneas are placed back in their original Deswelling-Transport bottle and transported at room temperature in a polystyrene box. Keratoplasty is usually performed within 4 days, with a total maximum exposure to Deswelling-Transport of 7 days. transfer of the cornea in Deswelling-Transport; T1, first sample after 1 day in Deswelling-Transport; T2, second sample of Deswelling-Transport after processing the cornea for lamellar keratoplasty

Sterility testing

We test the sterility of Storage and DeswellingTransport solutions with two validated automated systems to screen for microbial growth: Bactec 9240 (Becton-Dickinson, Franklin Lakes, NJ, USA) and HB\&L (Alifax, Padua, IT) have a recommended incubation period of 7 days and $24 \mathrm{~h}$, respectively (Camposampiero et al. 2013; Thuret et al. 2002). Samples are prepared under sterile conditions by injecting $3 \mathrm{~mL}$ of the preservation and the transport solution in the aerobic Bactec Peds Plus bottle and $3 \mathrm{~mL}$ in the anaerobic Bactec Plus bottle, and $0.5 \mathrm{~mL}$ in the HB\&L culture kit for growing aerobic microorganisms. The Bactec bottles can also grow fungi (Thuret et al. 2005). We use Bactec to test the Storage twice: after 6 days of culture (S1) and then again after assessing cornea suitability for transplantation $\geq 7$ days after S1 (S2), 1 day after transfer of the cornea into Deswelling-Transport (T1), and following processing of the cornea for lamellar keratoplasty (T2). We combine HB\&L for aerobic microorganisms and Bactec analysis in the second Storage sampling (S2), whereas we use both systems only at S1, T1, and $\mathrm{T} 2$ tests of corneas from donors at risk of microbial contamination (Fig. 1). 
Gram stain

We performed Gram stain to test the Storage at the end of organ-culture preservation (S2). After transfer of the cornea into the Deswelling-Transport solution, a volume of $50 \mathrm{~mL}$ of Storage was centrifuged $(4500$ rmp, $3893 \times g$ ) for $10 \mathrm{~min}$ in a sterile vial and the pellet suspended in $3 \mathrm{~mL}$ of sterile saline solution. A few drops of the suspended solution (mean $200 \mu \mathrm{L}$ ) were distributed over a microscope slide and air-dried for about $30 \mathrm{~min}$. The sample was heat-fixed by passing the slide over a flame until the underside was warm to the touch; the slide was then inserted into an automatic slide stainer (Wescor Aerospray Gram 7321, Delcon, Milan, IT) for automatic staining.

The microorganisms were stained with crystal violet (Gram-positive), which was then fixed to the wall with iodine, while the dye on the back of the slides was wiped clean with a cloth soaked in alcohol. To conclude the procedure, safranin was used to stain the decolorized Gram-negative microorganisms. Gram-positive microorganisms appear purple or blue and Gram negatives pink or red. The slides were observed under a light microscope (magnification $400 \times$ and $1000 \times$ ); samples were defined positive if they showed bacterial or fungal microorganisms differing by colour and cell morphology from eukaryotic cells of corneal origin.

\section{Statistical analysis}

We recorded the incidence of positive cultural microbial tests performed on Storage and DeswellingTransport solutions after completion of organ culture and compared the results for the year 2020 with the historical data (2015-2019), as well as in corneas from at-risk donors compared to corneas from not-at-risk donors in the year 2020. Incidence is expressed as number per 100 corneas.

The $\chi 2$ test was used to evaluate differences between year 2020 and the historical data (2015-2019) and between at-risk and not-at-risk donor corneas. The significance level was set at 0.05 and $95 \%$. Confidence intervals were calculated Statistical analysis was performed using STATA statistical software version 13 (StataCorp LP, College Station, TX, USA).

\section{Results}

Table 1 presents the results of culture tests for the 6-year period 2015-2020. We found no substantial difference in the number of donor corneas discarded due to a positive test result at $\mathrm{S} 1$ in $2020(\mathrm{~N}=171$, $3.9 \%)$ compared to the mean of $155(3.5 \%)$ for the previous five years $(p=0.21)$. The number of positive Storage and Deswelling-Transport solutions after culture tests of suitable corneas was $15(0.5 \%)$ in 2020 compared to a mean of $37(1.2 \%)$ positive solutions in the period 2015-2019 $(p<0.01)$. The difference was likely due to supplementation of the Cold solution with amphotericin B. There were 10 $(1.0 \%)$ positive samples in the cohort of 998 (32.8\%) donor corneas at risk and $5(0.2 \%)$ in the $2046(67.2 \%)$ corneas not at risk $(p<0.01)$. All at-risk corneas tested positive also at Gram stain and the test results were available 1 to 3 days before those from the culture tests performed according to our current protocol (Table 2). We identified by morphology Gram-positive cocci in 6 samples, fungal spores in 3, and Candida spp. in one sample (Fig. 2).

Deswelling-Transport at T2 was evaluated only for two corneas (nos. 12 and 13) processed for endothelial keratoplasty in corneas from not-at-risk donors. Both corneas were distributed for surgery while the $\mathrm{T} 1$ and the T2 sterility tests were ongoing; however, grafting was not performed because the test results became available (positive $\mathrm{T} 1$ and $\mathrm{T} 2$ in both cases) before the corneas arrived at the surgical centre. Additional Gram stain of the Deswelling-Transport of these two corneas showed Gram-positive cocci of Streptococcus spp.

\section{Discussion}

In the present study, we compared two methods potentially useful for improving the microbial safety of human corneas for transplantation. We discarded because of positive microbial tests at the end of organ culture less than half of the mean number of corneas discarded annually in the period 2015-2019 and we observed that amphotericin B $2.5 \mu \mathrm{g} / \mathrm{mL}$ added to the Cold solution is effective in reducing the primary contamination load. Furthermore, we compared the effectiveness of Gram stain and standard culture tests for early identification of residual microbial contaminants in the Storage solution. We noted that Gram 
Table 1 Results of sterility tests and postoperative adverse reactions recorded in 2015-2020 period

\begin{tabular}{|c|c|c|c|c|c|c|c|c|c|c|}
\hline Year & $\begin{array}{l}\text { Stored } \\
\text { corneas } \\
\mathrm{N}\end{array}$ & $\begin{array}{l}\mathrm{S} 1+ \\
\mathrm{N}(\%)\end{array}$ & $\begin{array}{l}\text { Suitable corneas } \\
\mathrm{N}\end{array}$ & S2 + only & $\mathrm{T}+$ only & $\begin{array}{l}\mathrm{S} 2+\text { and } \\
\mathrm{T}+ \\
\mathrm{N}(\%)^{*}\end{array}$ & $\begin{array}{l}\text { Positive } \\
\text { corneas } \\
\text { total } \\
\mathrm{N}(\%)^{*}\end{array}$ & $\begin{array}{l}\text { Positive } \\
\text { corneas } \\
\text { shipped } \\
\mathrm{N}(\%)^{* *}\end{array}$ & $\begin{array}{l}\text { Positive } \\
\text { corneas } \\
\text { grafted } \\
\mathrm{N}\end{array}$ & $\mathrm{AR}^{\S}$ \\
\hline 2015 & 3822 & $\begin{array}{c}181 \\
(4.7)\end{array}$ & 2674 & $13(0.5)$ & $16(0.6)$ & $6(0.2)$ & $35(1.3)$ & $15(42.9)$ & 1 & 1 \\
\hline 2016 & 4368 & $\begin{array}{l}156 \\
(3.6)\end{array}$ & 2862 & $12(0.4)$ & $8(0.3)$ & $4(0.1)$ & $24(0.8)$ & $5(20.8)$ & 0 & 0 \\
\hline 2017 & 4606 & $\begin{array}{l}110 \\
(2.4)\end{array}$ & 3125 & $31(1.0)$ & $9(0.3)$ & $3(0.1)$ & $43(1.4)$ & $7(16.7)$ & 5 & 1 \\
\hline 2018 & 4557 & $\begin{array}{l}143 \\
(3.1)\end{array}$ & 3022 & $22(0.7)$ & $10(0.3)$ & $9(0.3)$ & $41(1.4)$ & $11(26.8)$ & 2 & 0 \\
\hline 2019 & 4903 & $\begin{array}{c}184 \\
(3.7)\end{array}$ & 3154 & $21(0.7)$ & $13(0.4)$ & $8(0.2)$ & $42(1.3)$ & $11(26.2)$ & 1 & 1 \\
\hline 2020 & 4414 & $\begin{array}{l}171 \\
(3.9)\end{array}$ & 3044 & $8(0.3)$ & $2(0.1)$ & $5(0.2)$ & $15(0.5)$ & $2(0.1)$ & 0 & 0 \\
\hline Total & 26,670 & $\begin{array}{l}945 \\
(3.5)\end{array}$ & 17,881 & $107(0.6)$ & $58(0.3)$ & $35(0.2)$ & $200(1.1)$ & $51(25.5)$ & 9 & 3 \\
\hline
\end{tabular}

Bold represent the total values in each column

*Percentage on suitable corneas; **Percentage on positive corneas total; AR, adverse reaction; ${ }^{\S}$ Of the 3 cases of endophthalmitis post keratoplasty, that in 2015 was associated to Fusarium spp. contamination, that in 2019 to Candida spp., and the one in 2017 was of undetermined aetiology though reportedly due to the donor cornea according to the surgeon opinion, despite negative microbial testing at the eye bank

stain yielded positive results 1 to 3 days before the culture tests.

In general, antibiotic activity against fungi in preservation solutions is not seen at the first sterility test (S1) after the start of organ culture because of the slow growth of microbes and the latency in detection by culture systems. The effect of amphotericin B on the initial microbial load became evident in the test at the end of organ culture (S2) since prolonged storage at $30-37{ }^{\circ} \mathrm{C}$ increases the likelihood of microbial growth and the proliferation of microorganisms, mainly molds and yeasts. Direct microscopy detection of fungal structures following Gram stain improved the real-time identification of slow-growing microbes in 4 out of 10 positive stains in our study.

Contamination remains a problem, however, as shown by the two cases of microbial positive corneas pre-cut for DSAEK that did not undergo Gram stain. Gram stain should be extended to low-risk corneas to assess the accuracy of this procedure in comparison to standard culture methods in the early detection of microbial contaminants and hence prompt discarding of the corneas.
The growing demand for human corneas for transplantation and the expanding involvement of eye banks in the supply of pre-prepared ready-to-use corneal tissues for endothelial or anterior lamellar grafts, place added time pressure on the eye bank, chiefly during the deswelling and the delivery stage. The need to transplant tissues within 4 days after processing for lamellar keratoplasty limits the efficacy of culture sterility tests because the corneas are delivered before the culture tests are concluded at S2 and T1/T2. Microbial culture tests based on growthdependent systems can create overly long waiting times. So how can we ensure both safety and prompt delivery?

Our study results could open a new scenario in the evaluation of the sterility of organ-cultured corneas: coupling the Gram stain procedure with culture systems could align organ culture with organ delivery. The pressing demand for corneas and the ongoing shortage of donor corneas have shortened the preservation time (in 2020 the average in our institution was 14 days); less time is allotted for deswelling and transport of corneas for EK and DSAEK. In corneas processed for ALK or EK/DMEK, sterility at T1 and 
Table 2 Characteristics of microbial-positive corneas in 2020

\begin{tabular}{|c|c|c|c|c|c|c|c|c|}
\hline No. & $\begin{array}{l}\text { Intended } \\
\text { graft }\end{array}$ & Gram stain & $\begin{array}{l}\text { S2 } \\
\text { Bactec }\end{array}$ & $\begin{array}{l}\text { S2 } \\
\text { HB\&L }\end{array}$ & $\begin{array}{l}\text { T1 } \\
\text { Bactec }\end{array}$ & $\begin{array}{l}\text { T1 } \\
\text { HB\&L }\end{array}$ & $\begin{array}{l}\text { Results of Gram before Bactec/HB\&L } \\
\text { (days) }\end{array}$ & Shipped \\
\hline 1 & PK & $\begin{array}{l}\text { Cocci } \\
\text { Gram+ }\end{array}$ & + & + & ND & ND & 1 & No \\
\hline 2 & PK & Candida spp & + & + & - & ND & 1 & No \\
\hline 3 & PK & $\begin{array}{l}\text { Fungal } \\
\text { spores }\end{array}$ & + & - & + & ND & 3 & No \\
\hline 4 & PK & $\begin{array}{l}\text { Cocci } \\
\text { Gram }+\end{array}$ & + & - & + & - & 2 & No \\
\hline 5 & DSAEK & $\begin{array}{l}\text { Fungal } \\
\text { spores }\end{array}$ & + & - & - & ND & 2 & No \\
\hline 6 & PK & $\begin{array}{l}\text { Fungal } \\
\text { spores }\end{array}$ & + & + & ND & ND & 1 & No \\
\hline 7 & PK & $\begin{array}{l}\text { Cocci } \\
\text { Gram }+\end{array}$ & + & + & ND & ND & 1 & No \\
\hline 8 & PK & $\begin{array}{l}\text { Cocci } \\
\text { Gram+ }\end{array}$ & + & + & ND & ND & 1 & No \\
\hline 9 & PK & $\begin{array}{l}\text { Cocci } \\
\text { Gram }+\end{array}$ & + & - & ND & ND & 1 & No \\
\hline 10 & PK & $\begin{array}{l}\text { Cocci } \\
\text { Gram+ }\end{array}$ & + & - & + & ND & 3 & No \\
\hline 11 & PK & NA & + & + & ND & ND & NA & No \\
\hline $12^{*}$ & DSAEK & NA & - & - & + & - & NA & Yes** \\
\hline $13^{*}$ & DSAEK & NA & - & - & + & ND & NA & Yes** \\
\hline 14 & PK & NA & + & - & + & ND & NA & No \\
\hline 15 & PK & NA & + & + & + & ND & NA & No \\
\hline
\end{tabular}

*Cultural tests positive also at T2; **Not transplanted; DSAEK denotes Descemet stripping automated endothelial keratoplasty; NA not applicable, $N D$ not done, $P K$ penetrating keratoplasty

T2 may coincide or differ by a few hours, with delivery of the graft— to ensure its quality-on the same or the next day. The non-reactivity of the Storage solution at Gram stain and the maintenance of asepsis during processing for ready-to-use corneas could ensure a sufficient level of microbial safety and make the current culture tests on the Deswelling-Transport redundant.

When we process corneas from Storage to Deswelling-Transport (sterility testing is mandatory when transferring the cornea) and prepare them for ALK or EK/DMEK, we sample at T1 and T2 so that we can be sure that fungal contaminants have been eliminated and the corneas from Gram-positive Storage have been discarded, although positive results can be expected.
Finally, given the worldwide shortage of cornea donations, Gram stain should be adopted for rapid identification of microbial contaminants. This would aid surgeons in selecting appropriate preventive antibiotics and antifungal drugs, though grafts with a positive rim culture do not tend to result in postoperative infections (Li et al. 2019a, b).

A major limitation of Gram stain is that it is operator-dependent; nevertheless, we believe that it can be efficiently managed for consistent and reproducible results by automatic staining of slides and that basic microbiology and histology skills can help shorten the learning curve for microbial identification.

Based on our data, supplementation with amphotericin B $2.5 \mu \mathrm{g} / \mathrm{mL}$ in the short-term hypothermic maintenance solution and Gram staining of storage solutions at the end of organ culture offer successful 


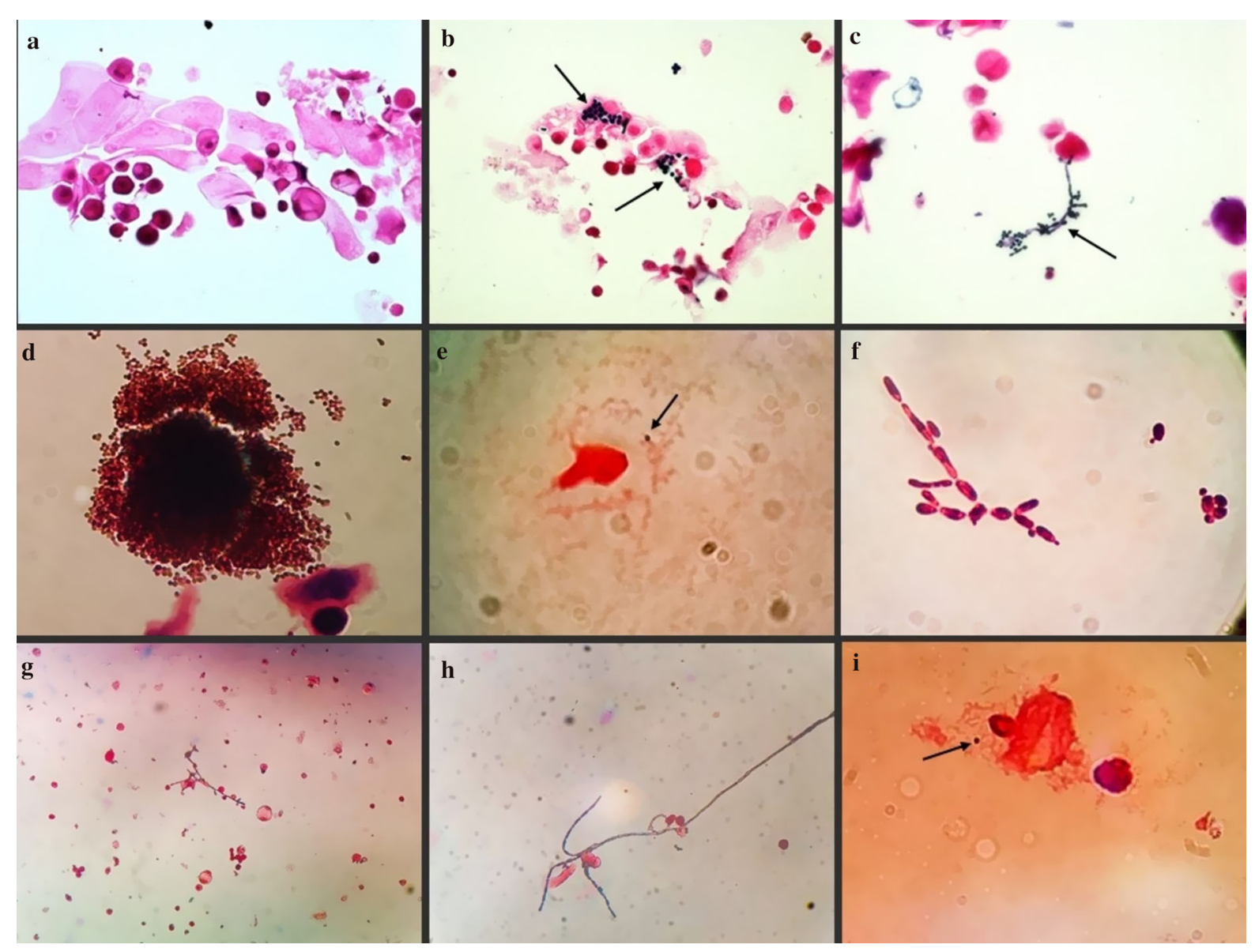

Fig. 2 Example images of Gram stain results. a Superficial squamous corneal epithelia and cells with vacuolated cytoplasm of likely conjunctival origin; Gram staining negative for microorganisms; b aggregates of sporiform Gram-positive elements, likely Candida spp.; c pseudohyphae and blastospores of a Gram-positive yeast, likely Candida spp.; d massive aggregates of blastospores; e Gram-positive cocci and squamous

strategies to reduce the initial microbial load, to detect residual microbial contaminants promptly, and to discard contaminated corneas. Both strategies may help to improve the safety of corneal tissues and reduce the rate of postoperative infectious keratitis caused by slow-growing microorganisms such as moulds and yeasts.

Authors' contributions DC research design, data evaluation, manuscript writing; AF: data evaluation, manuscript writing; GS data collection and analysis; PMD data analysis; EZ data collection and analysis, manuscript approval; DP manuscript revision. epithelial corneal cells; f pseudohyphae and chlamydospore of Candida spp.; $\mathbf{g}$ fungal hypha among epithelial corneal cells; $\mathbf{h}$ enlarged detail of fungal hypha; $\mathbf{i}$ enlarged image of Grampositive cocci. Images a-c, magnification $\times 400$; images $\mathbf{d}-\mathbf{g}$, magnification $\times 1000$; images $\mathbf{d}-\mathbf{i}$ acquired directly from the eyepiece of the light microscope

\section{Funding None.}

Availability of data and material Data and material are available for users granted access.

\section{Declarations}

Conflict of interest The authors have no conflict of interest to declare.

Ethical approval Not required because the study did not affect current procedures for sterility testing and safety of corneal tissues at the Eye Bank.

Open Access This article is licensed under a Creative Commons Attribution 4.0 International License, which permits use, sharing, adaptation, distribution and reproduction 
in any medium or format, as long as you give appropriate credit to the original author(s) and the source, provide a link to the Creative Commons licence, and indicate if changes were made. The images or other third party material in this article are included in the article's Creative Commons licence, unless indicated otherwise in a credit line to the material. If material is not included in the article's Creative Commons licence and your intended use is not permitted by statutory regulation or exceeds the permitted use, you will need to obtain permission directly from the copyright holder. To view a copy of this licence, visit http://creativecommons.org/licenses/by/4.0/.

\section{References}

Aldave AJ, DeMatteo J, Glasser DB, Tu EY, Iliakis B, Nordlund ML, Misko J, Verdier DD, Yu F (2013) Report of the Eye Bank Association of America medical advisory board subcommittee on fungal infection after corneal transplantation. Cornea 32:149-154. https://doi.org/10.1097/ICO. 0b013e31825e $83 \mathrm{bf}$

Armitage WJ, Jones MN, Zambrano I, Carley F, Tole DM (2014) The suitability of corneas stored by organ culture for penetrating keratoplasty and influence of donor and recipient factors on 5-year graft survival. Invest Ophthalmol vis Sci 55:784-791. https://doi.org/10.1167/iovs.1313386

Camposampiero D, Grandesso S, Zanetti E, Mazzucato S, Solinas M, Parekh M, Frigo AC, Gion M, Ponzin D (2013) Evaluation of the HB\&L System for the microbiological screening of storage medium for organ-cultured corneas. J Ophthalmol 2013:670947. https://doi.org/10.1155/2013/ 670947

Camposampiero D, Zanetti E, Calvo R, de Mora M, Grandesso S (2015) Microbiology in eye banking. In: Parek M, Ferrari S, Ponzin D (eds) Eye banking: changing face of corneal transplantation, 1st edn. Nova Science Publishers, New York, pp 157-168

Edelstein SL, DeMatteo J, Stoeger CG, Macsai MS, Wang CH (2016) Report of the Eye Bank Association of America medical review subcommittee on adverse reactions reported from 2007 to 2014. Cornea 35:917-926. https://doi.org/ 10.1097/ICO.0000000000000869

EEBA (2020) European Eye Bank Association. Technical guidelines for ocular tissue (Revision 11). https://www. eeba.eu/files/pdf/EEBA_Technical_Guidelines_for_ Ocular_Tissue_Revision11. Accessed 1 June 2021

Fontana L, Errani PG, Zerbinati A, Musacchi Y, Di Pede B, Tassinari G (2007) Frequency of positive donor rim cultures after penetrating keratoplasty using hypothermic and organ-cultured donor corneas. Cornea 26:552-556. https:// doi.org/10.1097/ICO.0b013e3180415d7e

Kiatos E, Armstrong JJ, Hutnik CM, Tsioros SM, MalvankarMehta MS, Hodge WG (2017) The value of corneoscleral rim cultures in keratoplasty: a systematic review and costeffectiveness analysis. Clinicoecon Outcomes Res 9:459-474. https://doi.org/10.2147/CEOR.S139949

Kitazawa K, Wakimasu K, Yoneda K, Iliakis B, Sotozono C, Kinoshita S (2017) A case of fungal keratitis and endophthalmitis post penetrating keratoplasty resulting from fungal contamination of the donor cornea. Am J Ophthalmol Case Rep 5:103-106. https://doi.org/10.1016/ j.ajoc.2016.12.015

Kramp K, Suffo S, Laun D, Bischoff-Jung M, Huber M, Langenbucher A, Seitz B (2020) Analysis of factors influencing the suitability of donor corneas in the LIONS Cornea Bank Saar-Lor-Lux, Trier/Westpfalz from 2006 to 2016. Klin Monbl Augenheilkd 237:1334-1342. https://doi.org/ 10.1055/a-1141-3703

Li GG, Zhu H, Ji CN, Zang XJ (2019a) Microbiological contamination in donor corneas preserved for medium-term. Cell Tissue Bank 20:379-387. https://doi.org/10.1007/ s10561-019-09776-5

Li S, Zhong J, Tan Y, Deng Y, Huang H, Wang B, Peng L, Zhang H, Yuan J (2019b) Microbiological screening of hypothermic preserved donor corneas in keratoplasty. Curr Eye Res 44:1067-1074. https://doi.org/10.1080/02713683. 2019.1616766

Ling MLH, Wells M, Petsoglou C, Luo K, Georges P, Devasahayam R, Hodge C, Treloggen J, Sutton G, Zhu M (2019) Factors affecting corneal organ culture contamination: a 6-year study at the New South Wales tissue bank. Cornea 38:829-835. https://doi.org/10.1097/ICO. 0000000000001936

Murray PR, Rosenthal KS, Pfaller MA (2012) Medical microbiology, 7th edn. Elsevier, Nederlands

Popescu A, Doyle RJ (1996) The Gram stain after more than a century. Biotech Histochem 71:145-151. https://doi.org/ 10.3109/10520299609117151

Röck T, Hofmann J, Thaler S, Bramkamp M, Bartz-Schmidt KU, Yoeruek E, Röck D (2016) Factors that influence the suitability of human organ-cultured corneas. Graefes Arch Clin Exp Ophthalmol 254:135-141. https://doi.org/10. 1007/s00417-015-3119-7

Thareja T, Kowalski R, Kamyar R, Dhaliwal D, Jeng BH, Tu E, Jhanji V (2020) Fungal infection after keratoplasty and the role of antifungal supplementation to storage solution: a review. Br J Ophthalmol 104:1036-1039. https://doi.org/ 10.1136/bjophthalmol-2019-314664

Thomas P (2003) Fungal infections of the cornea. Eye 17:852-862. https://doi.org/10.1038/sj.eye.6700557

Thuret G, Carricajo A, Chiquet C, Vautrin AC, Celle N, Boureille M, Acquart S, Aubert G, Maugery J, Gain P (2002) Sensitivity and rapidity of blood culture bottles in the detection of cornea organ culture media contamination by bacteria and fungi. Br J Ophthalmol 86:1422-1427. https:// doi.org/10.1136/bjo.86.12.1422

Thuret G, Carricajo A, Vautrin AC, Raberin H, Acquart S, Garraud O, Gain P, Aubert G (2005) Efficiency of blood culture bottles for the fungal sterility testing of corneal organ culture media. Br J Ophthalmol 89:586-590. https:// doi.org/10.1136/bjo.2004.053439

Tran KD, Aldrich BT, D’Amato Tóthová J, Skeie JM, Kondratick CM, Giurgola L, Gatto C, Reed CR, Schmidt GA, Terry MA, Greiner MA (2020) Efficacy and safety of various amphotericin B concentrations on Candida albicans in Cold storage conditions. Cornea 39:110-117. https://doi.org/10.1097/ICO.0000000000002019

Zanetti E, Bruni A, Mucignat G, Camposampiero D, Frigo AC, Ponzin D (2005) Bacterial contamination of human organ- 
cultured corneas. Cornea 24:603-607. https://doi.org/10. 1097/01.ico.0000153099.96904.43
Publisher's Note Springer Nature remains neutral with regard to jurisdictional claims in published maps and institutional affiliations. 